\title{
Risk for atrial fibrillation in patients with hypertrophic cardiomyopathy assessed by signal averaged $\mathrm{P}$ wave duration
}

Franco Cecchi, Alessio Montereggi, Iacopo Olivotto, Paolo Marconi, Alberto Dolara, Barry J Maron

\begin{abstract}
Objective-To assess the relation between $P$ wave duration and the occurrence of atrial fibrillation in hypertrophic cardiomyopathy (HCM).

Design-High resolution signal averaged electrocardiography was used in 110 patients with HCM to determine whether patients at risk for paroxysmal atrial fibrillation could be detected during sinus rhythm by measuring $P$ wave duration. Filtered $P$ wave duration was measured manually, over an average of 300 beats per patient.
\end{abstract}

Results-During follow up, 18 patients $(16 \%)$ had at least one one clinical episode of paroxysmal atrial fibrillation, including four patients whose initial episode followed the signal averaged electrocardiogram. The 18 patients with overt atrial fibrillation had greater $P$ wave duration than the 69 patients who did not develop atrial fibrillation: 150 (SD 20) $v 126$ (14) ms; $\mathbf{P}<0.001$. Another 23 patients without clinically evident atrial fibrillation had prolonged bursts of the arrhythmia on Holter recording, and showed a $P$ wave duration (138 (15) ms) intermediate between patients with and without clinical atrial fibrillation. In assessing risk for atrial fibrillation, $P$ wave duration $\geqslant 140 \mathrm{~ms}$ was associated with sensitivity, specificity, and positive predictive accuracy values of $56 \%, 83 \%$, and $66 \%$. Multivariate analysis showed that duration of the $P$ wave was the only independent variable associated with occurrence of atrial fibrillation; if $P$ wave duration $\geqslant 140 \mathrm{~ms}$ was combined with left atrial enlargement $>40 \mathrm{~mm}$, the specificity and positive predictive accuracy for atrial fibrillation increased to $93 \%$ and $78 \%$.

Conclusions-Measurement of $P$ wave duration in sinus rhythm by high resolution signal averaged electrocardiography may be a useful non-invasive clinical tool for identifying patients with HCM likely to develop electrical instability and atrial fibrillation.

(Heart 1997;78:44-49)

Keywords: hypertrophic cardiomyopathy; atrial fibrillation; signal averaged ECG; prognosis

Atrial fibrillation may be a relatively common clinical event in patients with hypertrophic cardiomyopathy (HCM), often leading to clinical deterioration or death. ${ }^{1-9}$ Therefore, the early detection of patients with HCM at risk for developing atrial fibrillation may be useful in developing preventive measures and treatment strategies.

Measurement of $\mathrm{P}$ wave duration using a high resolution signal averaged electrocardiogram has been proposed as a non-invasive and reproducible method for assessing risk for atrial fibrillation in cardiac diseases other than HCM..$^{10-13}$ Several studies have shown a good correlation between the duration of the $P$ wave and the occurrence of atrial fibrillation in patients with coronary artery disease ${ }^{14}$ and hyperthyroidism, ${ }^{15}$ as well as in the absence of structural heart disease. ${ }^{11131617}$ In the present study we used the signal averaged electrocardiogram for the first time in patients with hypertrophic cardiomyopathy to assess the relation between $P$ wave duration and the occurrence of atrial fibrillation.

\section{Methods}

PATIENT SELECTION

This study was conducted in a retrospective and prospective fashion between September 1988 and December 1993. The study group comprised 110 consecutively enrolled patients with HCM evaluated in the outpatient cardiology clinic of the Ospedale di Careggi, Florence, without either chronic atrial fibrillation, an implanted pacemaker, or frequent supraventricular ectopic beats $(>1 \%$ of cycles on prior Holter ECG). Six other eligible patients declined the signal averaged electrocardiogram and were excluded from the analysis. Duration of patient follow up was 8 (SD 5) years from initial diagnosis to the time of signal averaged electrocardiogram recording, and $4(0.8)$ years after the recording, with an overall follow up of 12 (6) years (range 2 to 31 ). As previously described, ${ }^{8}$ each patient was evaluated routinely with non-invasive testing on an annual basis.

\section{CHARACTERISATION OF STUDY PATIENTS}

The patients' age at the time of the signal averaged electrocardiogram recording was 46 (15) years (range 11 to 76$) ; 83(75 \%)$ were men. At that time, 55 patients were asymptomatic, 40 had experienced mild symptoms (New York Heart Association class II), and 15 had severe symptoms (classes III-IV). Thirty two patients did not receive medical treatment. In the remaining 78 patients one or more of the following drugs was given in a virtually continu- 
ous fashion and in standard dosages: $\beta$ blockers (48 patients; $44 \%$ ), calcium antagonists (46 patients; $42 \%$ ), and amiodarone (27 patients; $24 \%)$.

Diagnosis of HCM was based on the echocardiographic finding of a hypertrophied, non-dilated left ventricle in the absence of any cardiac or systemic disease capable of producing the magnitude of hypertrophy evident in that patient. ${ }^{18}$ Echocardiographic assessment showed maximum left ventricular thickness of 23 (5) $\mathrm{mm}$ (range 13 to 41 ), usually involving predominantly the anterior ventricular septum. ${ }^{19}$ Left ventricular end diastolic cavity dimension was 43 (6) $\mathrm{mm}$ (range 27 to 56 ) and per cent fractional shortening was 40 (8) (range 21 to 60 ). A basal left ventricular outflow tract gradient ( $>30 \mathrm{~mm} \mathrm{Hg}$ ) was documented by continuous wave Doppler ${ }^{20} 21$ in 23 patients $(21 \%)$.

Fifty healthy subjects without evidence of cardiovascular disease were selected as controls. Mean age was 50 (12) years (range 21 to 72 ), which did not differ significantly from that of patients with $\mathrm{HCM} ; 26(52 \%)$ were men.

\section{DOCUMENTATION OF ATRIAL FIBRILLATION} Among the 110 study patients, three subgroups were identified: (1) 69 patients without evidence of atrial fibrillation, either under clinical circumstances or on ambulatory Holter monitoring; (2) 23 patients without clinically evident atrial fibrillation, in whom one or more runs of atrial fibrillation were identified

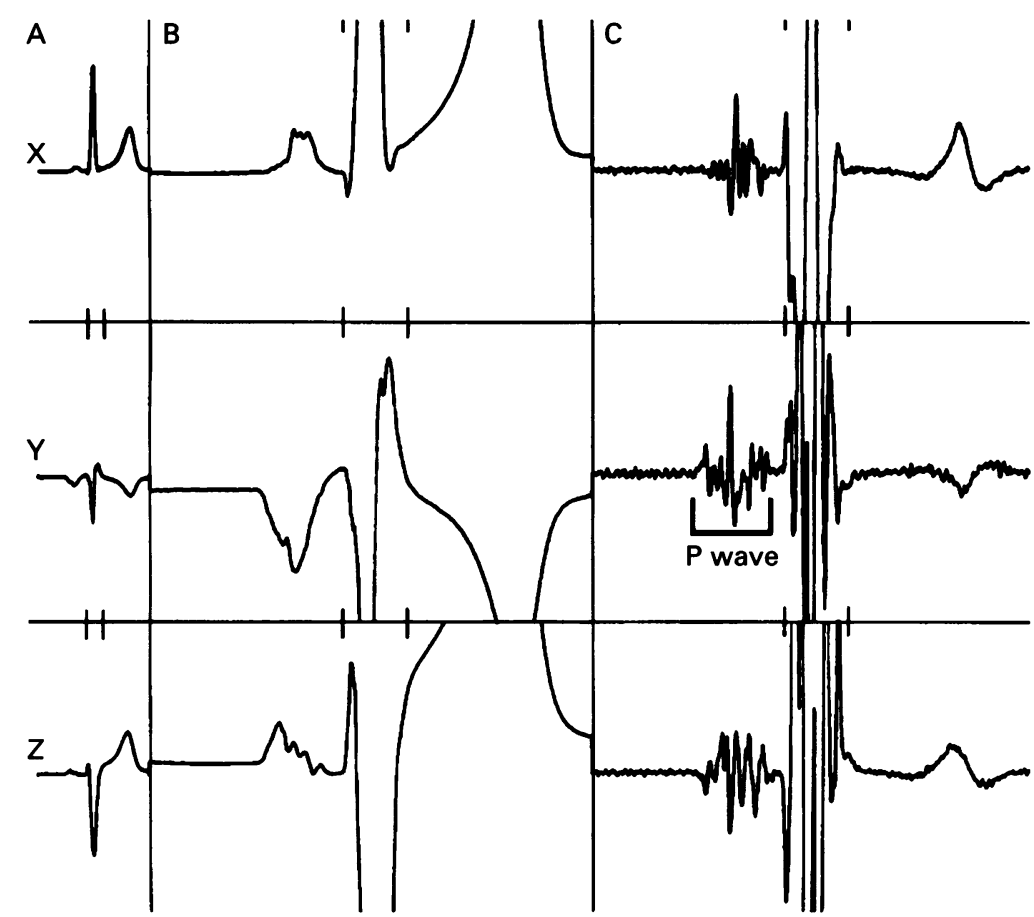

Figure 1 Example of high resolution electrocardiogram obtained on a 42 year old study patient for the measurement of $P$ wave duration. The three orthogonal leads $X, Y$, and $Z$ were recorded as described in the text. (A) (panels on left): Speed $25 \mathrm{~mm} / \mathrm{s}$. High filter $250 \mathrm{~Hz}$; low filter absent. (B) (middle panels): Speed $100 \mathrm{~mm} / \mathrm{s}$, and amplitude 1 $\mathrm{mm} / \mu \mathrm{V}$. High filter: $250 \mathrm{~Hz}$; low filter: absent. (C) (panels on right): Speed $100 \mathrm{~mm} / \mathrm{s}$ $\mathrm{mm} / \mu \mathrm{V}$. High filter: $250 \mathrm{~Hz}$; low filter: absent. (C) (panels on right): Speed $100 \mathrm{~mm} / \mathrm{s}$
and amplitude $1 \mathrm{~mm} / \mu \mathrm{V}$. High filter: $250 \mathrm{~Hz}$; low filter: $50 \mathrm{~Hz}$. P wave duration was measured as the time interval from the beginning to the end of a signal having more than twice the noise amplitude at baseline (usually $<0.3 \mu \mathrm{V}$ ), and taken as the longest measured interval in any of the leads (usually the $Y$ ). solely on at least one $48 \mathrm{~h}$ Holter ECG recording (usually unassociated with symptoms); and (3) 18 patients with one or more clinically evident episodes of atrial fibrillation, including 10 patients with one to four additional paroxysms after the initial event. Of the latter 18 patients, 14 were known to have had at least one episode of paroxysmal atrial fibrillation before the signal averaged electrocardiogram recording; in the other four patients, the initial episode of atrial fibrillation occurred six months to 2.5 years after the recording. In each of these patients a prolonged episode of atrial fibrillation was responsible for new symptoms such as dyspnoea, palpitations, presyncope and syncope, prompting the patient to seek medical assistance with subsequent documentation of the arrhythmia by standard electrocardiogram. Of the 18 patients with clinical atrial fibrillation, 14 required pharmacological or electrical cardioversion for one or more paroxysms of atrial fibrillation, while the remaining four patients had single episodes that reverted spontaneously to sinus rhythm.

SIGNAL AVERAGED ELECTROCARDIOGRAM All study patients were in sinus rhythm at the time the signal averaged electrocardiogram was performed. Cardioactive drugs (with the exception of amiodarone) were withdrawn for at least five half lives before the recording.

$\mathbf{P}$ wave analysis was performed with high resolution electrocardiographic equipment (1200 EPX, Arrhythmia Research Technology, Austin, Texas, USA), collecting an average of 300 cycles (range 200 to 500 ) in each patient. ${ }^{22}$ Noise was considered acceptable when below $0.4 \mu \mathrm{V}$. Recordings were performed at $100 \mathrm{~mm} / \mathrm{s}$ paper speed with a bidirectional digital filter ( 50 and $250 \mathrm{~Hz}$ ). Three bipolar orthogonal leads $(\mathrm{X}, \mathrm{Y}, \mathrm{Z})$ were used according to Simson's technique. ${ }^{22}$ The standard lead I was used as the $\mathrm{X}$ lead, aVF was the $Y$ lead, and a bipolar lead corresponding to the position of precordial lead $V_{1}$ was used as the $Z$ lead. We employed a conventional $\mathbf{R}$ wave triggered technique for signal averaging. ${ }^{13161723}$ Duration of the filtered P wave was measured manually as the time interval from the beginning to the end of a signal characterised by having more than twice the basal noise amplitude (usually $<0.3 \mu \mathrm{V}$ ), and taken as the longest interval in any of the leads (usually the Y lead) (fig 1). Measurements were made by two observers (AM and PM) without knowledge of the identity of the patients.

HOLTER MONITORING

Each of the 110 study patients had at least one standard 24 or 48 hour Holter ECG recording (Del Mar Avionics, Irvine, California, USA) during the period of follow up. Holter studies after the initial recording were obtained routinely (often on an annual basis) or based on clinical findings such as cardiac symptoms or previously identified arrhythmias. The number of Holter monitoring days per year during the period of follow up did not differ between the 
Figure 2 Comparison of left atrial dimension in 69 patients without atrial fibrillation $(A F), 23$ patients with atrial fibrillation only on Holter ambulatory ECG and 18 patients with clinically evident atrial fibrillation. Empty symbols in the clinical $A F$ group represent the four patients who initially developed clinical atrial fibrillation after the recording of the signal averaged electrocardiogram.

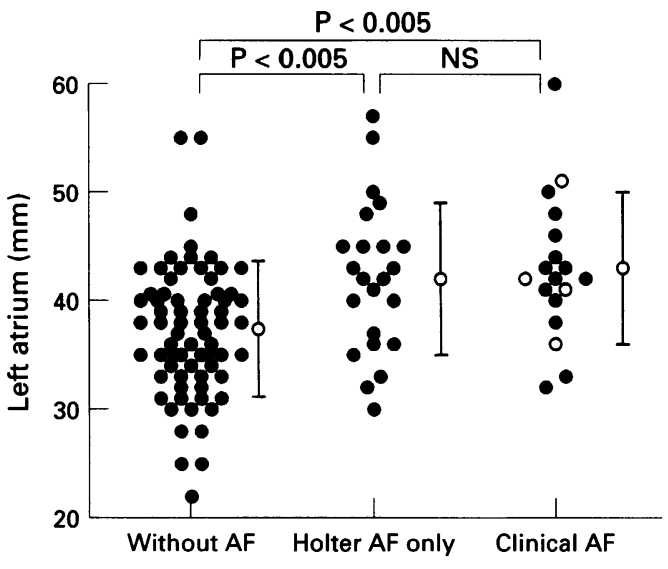

patients who proved to have atrial fibrillation, either clinically overt $(0.6 \quad(0.5)$ days $)$ or identified only on Holter ( $0.8(0.6)$ days), and those without atrial fibrillation $(0.7(0.4)$ days).

\section{INTEROBSERVER AND INTRAOBSERVER \\ VARIABILITY}

Interobserver and intraobserver variability in the measurement of $\mathbf{P}$ wave duration was assessed in a subgroup of 100 subjects (50 controls and 50 patients). To determine interobserver variability, the two independent investigators measured the $\mathbf{P}$ wave duration on the signal averaged electrocardiogram without knowledge of the identity of subjects. To determine intraobserver variability, one observer (AM) also measured $P$ wave duration in the same tracing on two occasions (two months apart).

\section{STATISTICAL ANALYSIS}

Data are expressed as mean (SD). Comparison of means was performed using Student's $t$ test or the Mann-Whitney U test; $\chi^{2}$ or Fisher's exact tests were employed in the analysis of discrete variables where appropriate. To establish correlations between continuous variables, Pearson's correlation coefficient was obtained using linear regression analysis. To identify variables independently associated with the occurrence of prolonged $\mathrm{P}$ wave duration or atrial fibrillation, univariate and multivariate logistic regression analysis was performed. ${ }^{24}$

\section{Results}

LEFT ATRIAL DIMENSION

Left atrial dimension, assessed by echocardiography, was significantly greater in patients with clinical atrial fibrillation than in patients without atrial fibrillation (fig 2; table 1). Left atrial dimension in the 23 patients with atrial fibrillation only on Holter also exceeded that of patients without atrial fibrillation, but did not differ from patients with clinical atrial fibrillation (fig 2; table 1). A weak linear relation was present between left atrial dimension and $\mathbf{P}$ wave duration for the overall study group ( $r=$ $0.36 ; \mathrm{P}<0.001$ ).

\section{P WAVE DURATION}

Comparison of patients with hypertrophic cardiomyopathy and controls

$P$ wave duration in the 110 patients with HCM (132 (17) ms; range 100 to 200) exceeded that in the 50 healthy controls (113 (11) $\mathrm{ms}$; range 90 to $132 ; \mathrm{P}<0.001$ ) (fig 3 ). Values for $P$ wave duration in 46 of the 110 patients with HCM $(42 \%)$ were greater than those of all control subjects.

Comparison of subgroups of patients with hypertrophic cardiomyopathy

$P$ wave duration in the 18 patients with clinical atrial fibrillation exceeded that in the 69 patients without atrial fibrillation $(P<0.001)$ (fig 4 ; table 1). In the 23 patients with atrial fibrillation detected only by Holter monitoring, $\mathbf{P}$ wave duration was intermediate between the other two patient subgroups: longer than in patients without atrial fibrillation $(P<0.005)$, and shorter than in patients with clinically evident atrial fibrillation $(P<0.05)$ (fig 4). During the period of follow up, none of these patients had developed clinically discernible atrial fibrillation; however, 11 of the 15 patients with clinical atrial fibrillation who had had Holter monitoring before their signal averaged electrocardiogram recording were known to have had at least one asympto-

Table 1 Clinical and echocardiographic features and signal averaged electrocardiographic data in 110 patients with hypertrophic cardiomyopathy. Values are mean $(S D)$, or (\%) where indicated

\begin{tabular}{|c|c|c|c|c|c|c|c|c|c|c|c|}
\hline & $\begin{array}{l}\text { Age } \\
\text { (years) }\end{array}$ & $\begin{array}{l}\text { Sex } \\
(n, \% \\
\text { male })\end{array}$ & $\begin{array}{l}\text { NYHA } \\
\text { class }\end{array}$ & $\begin{array}{l}\text { Maximum } \\
\text { LV } \\
\text { thickness } \\
(\mathrm{mm})\end{array}$ & $\begin{array}{l}\text { Left } \\
\text { atrium } \\
(\mathrm{mm})\end{array}$ & $\begin{array}{l}L V D \\
(\mathrm{~mm})\end{array}$ & $\begin{array}{l}\text { Fractional } \\
\text { shortening } \\
(\%)\end{array}$ & $\begin{array}{l}\text { LV outflow } \\
\text { gradient } \\
(>30 \mathrm{~mm} \mathrm{Hg}) \\
(n, \%)\end{array}$ & $\begin{array}{l}\text { Follow up } \\
\text { after } \\
\text { SAECG } \\
\text { (years) }\end{array}$ & $\begin{array}{l}\text { Follow up } \\
\text { after } \\
\text { diagnosis } \\
\text { (years) }\end{array}$ & $\begin{array}{l}P \text { wave } \\
\text { duration } \\
\text { (ms) }\end{array}$ \\
\hline $\begin{array}{l}\text { Without AF } \\
(n=69)\end{array}$ & $42(15)$ & $52(75)$ & $1.4(0.6)$ & $23(5)$ & $37(6)$ & $43(6)$ & $40(8)$ & $10(14)$ & $4 \cdot 0(0 \cdot 8)$ & $10 \cdot 8(5 \cdot 7)$ & $126(14)$ \\
\hline $\begin{array}{l}\text { Holter AF } \\
(n=23)\end{array}$ & $59(11) \dagger$ & $15(65)$ & $1.8(0.6) \ddagger$ & $23(5)$ & $42(7) \dagger$ & $44(6)$ & $38(7)$ & $4(17)$ & $3.9(0.7)$ & $13 \cdot 1(6 \cdot 8)$ & $138(15) \dagger$ \\
\hline $\begin{array}{l}\text { Clinical AF } \\
(n=18)\end{array}$ & $54(12) \ddagger$ & $16(89)$ & $2 \cdot 2(0.8) \dagger$ & $25(6)$ & $43(7) \dagger$ & $44(6)$ & $39(6)$ & $9(50) \dagger^{\star \star}$ & $3.9(1.0)$ & $14 \cdot 3(7 \cdot 8) \ddagger$ & $150(20) t^{\star \star \star}$ \\
\hline $\begin{array}{l}\text { Univariate } \\
\text { analysis }\end{array}$ & $P<0.05$ & NS & $P<0.05$ & NS & $P<0.01$ & NS & NS & NS & NS & $P<0.05$ & $P<0.001$ \\
\hline Multivariates & NS & NS & NS & NS & NS & NS & NS & NS & NS & NS & $P=0.002$ \\
\hline
\end{tabular}

nalysis

AF, atrial fibrillation; LV, left ventricular; LVD, left ventricular end-diastolic dimension; NYHA, New York Heart Association; SAECG, signal averaged electrocardiogram.

${ }^{\star}$ Assessed with echocardiography under basal conditions.

$+\mathrm{P}<0.005 v$ without $\mathrm{AF}$.

$\neq \mathrm{P}<0.05 v$ without $\mathrm{AF}$

Logistic regression analysis evaluating the association with $\mathrm{AF}$ (clinical or Holter). 
Figure 3 Comparison of filtered $P$ wave duration (as assessed by signal averaged

electrocardiogram) in 110 patients with hypertrophic cardiomyopathy (HCM) and 50 normal control subjects of similar age. Mean values were 132 (17) and 113 (11) ms, respectively.

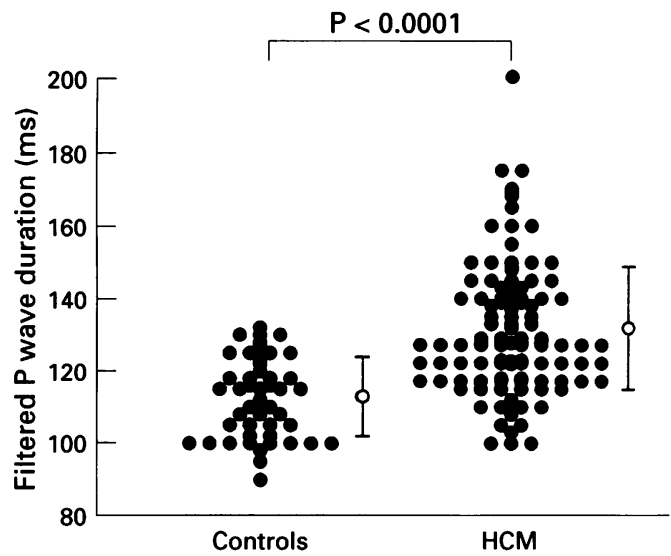

Figure 4 Comparison of filtered $P$ wave duration in 69 patients without atrial fibrillation $(A F), 23$ patients with atrial fibrillation only on Holter ambulatory

electrocardiogram and 18 patients with clinically evident atrial fibrillation. Empty symbols in the clinical $A F$ group represent the four patients who initially developed clinical atrial fibrillation after the recording of the signal averaged

electrocardiogram.

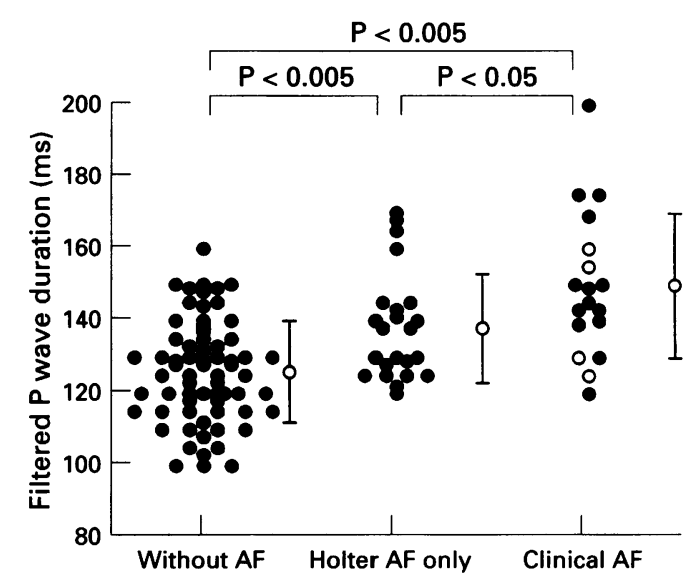

matic episode of atrial fibrillation on their ambulatory electrocardiogram.

Sensitivity, specificity, and predictive accuracy values for $P$ wave duration in assessing risk for developing clinical or Holter atrial fibrillation are summarised in table 2 . Intermediate $P$ wave duration of $\geqslant 140 \mathrm{~ms}$ proved to be the cut off with the best combination of sensitivity and specificity for atrial fibrillation ( $56 \%$ and $83 \%$ respectively), with a positive predictive accuracy of $66 \%$.

Multivariate analysis identified $\mathbf{P}$ wave duration as the only independent marker for the propensity to develop atrial fibrillation $(P=0.002)$ (table 1). When the criterion of $P$ wave duration of $\geqslant 140 \mathrm{~ms}$ was combined with left atrial dimension of $>40 \mathrm{~mm}$, the specificity and positive predictive accuracy improved to $93 \%$ and $78 \%$, respectively, although sensitivity was lower (44\%). For patients with prolonged $\mathbf{P}$ wave duration $(\geqslant 140 \mathrm{~ms})$ the odds ratio of having atrial fib-

Table 2 Sensitivity, specificity and predictive accuracy in assessing the risk for developing clinical or Holter atrial fibrillation using signal averaged $P$ wave duration in 110 patients with hypertrophic cardiomyopathy

\begin{tabular}{|c|c|c|c|c|c|c|}
\hline & \multicolumn{6}{|c|}{$P$ wave duration (ms) } \\
\hline & $\geqslant 120$ & $\geqslant 130$ & $\geqslant 140$ & $\geqslant 145$ & $\geqslant 150$ & $\begin{array}{l}\geqslant 140+ \\
L A>40 \mathrm{~mm}\end{array}$ \\
\hline \multirow{3}{*}{$\begin{array}{l}\text { Sensitivity (\%) } \\
\text { Specificity (\%) } \\
\text { Positive predictive } \\
\text { accuracy (\%) } \\
\text { Negative predictive } \\
\text { accuracy (\%) }\end{array}$} & $\begin{array}{l}95 \\
42\end{array}$ & $\begin{array}{l}63 \\
59\end{array}$ & $\begin{array}{l}56 \\
83\end{array}$ & $\begin{array}{l}39 \\
88\end{array}$ & $\begin{array}{l}29 \\
94\end{array}$ & $\begin{array}{l}44 \\
93\end{array}$ \\
\hline & 49 & 48 & 66 & 67 & 75 & 78 \\
\hline & 94 & 73 & 76 & 71 & 69 & 73 \\
\hline
\end{tabular}

LA, left atrium. rillation, adjusted for antiarrhythmic treatment, age, left atrial dimension, and functional class, was $3 \cdot 44(95 \%$ confidence interval $1 \cdot 12$ to $6 \cdot 25$ )

Impact of pharmacological treatment $P$ wave duration in the 27 patients taking amiodarone exceeded that in other patients, at 142 (17) $v 129$ (16) ms; P < 0.001. However, the $P$ wave prolongation caused by amiodarone treatment did not affect the difference in $\mathbf{P}$ wave duration between patients with and without atrial fibrillation. When those patients taking amiodarone were excluded from the analysis, the differences in $\mathbf{P}$ wave duration between the two groups remained substantially unchanged, at 142 (19) $\mathrm{ms}$ in patients with atrial fibrillation $v 124$ (13) $\mathrm{ms}$ in patients without atrial fibrillation; $P<0 \cdot 001$. Similarly, the difference in $P$ wave duration between patients with and without atrial fibrillation remained substantially unchanged when patients receiving $\beta$ blockers or calcium antagonists were excluded from the analysis (144 (22) vs. 125 (14) ms; P < 0.005; and 138 (13) vs. 126 (14) ms; $P<0.005$, respectively).

Multivariate regression analysis evaluated the association of several clinical variables (atrial fibrillation, left atrial size, NYHA functional class, age, and treatment with amiodarone, $\beta$ blockers, and calcium antagonists) with $\mathbf{P}$ wave prolongation (defined as $\geqslant 140 \mathrm{~ms}$ ). Although amiodarone treatment was associated with prolonged $P$ wave $(P<<$ $0.001)$, occurrence of atrial fibrillation retained a highly significant association with $P$ wave prolongation, independent of the effect of amiodarone administration $(P<0.001)$.

COMPARISON OF CLINICAL AND DEMOGRAPHIC

VARIABLES IN PATIENT SUBGROUPS

The 18 patients with clinical atrial fibrillation were older (54 (12) v 42 (15) years; $\mathrm{P}<0.05$ ), showed greater functional impairment (functional class $2.2(0.8) v 1.4(0.6) ; \mathrm{P}<0.005)$, and more commonly had obstruction to left ventricular outflow under basal conditions (gradient $>30 \mathrm{~mm} \mathrm{Hg}$ ) than the 69 patients without atrial fibrillation (table 1); no differences with respect to gender were evident (76\% male with and $75 \%$ male without atrial fibrillation. Left ventricular end diastolic dimension, per cent fractional shortening, and maximum wall thickness, as assessed by echocardiography, did not differ significantly between the two patient groups (table 1). With respect to these clinical and demographic variables, patients with atrial fibrillation on Holter were generally similar to those with clinical atrial fibrillation, although the latter more commonly showed outflow obstruction (table 1).

INTEROBSERVER AND INTRAOBSERVER

VARIABILITY

Interobserver variability

The mean difference between the two observers for measurement of the signal averaged $P$ wave duration was $2 \cdot 4(2 \cdot 2) \mathrm{ms}$. Interobserver variability was $2 \cdot 0(1.9) \%$. 
Intraobserver variability

The difference between the two measurements of $P$ wave duration made by the same observer was $1.8(1.5) \mathrm{ms}$. Intraobserver variability was $1 \cdot 4(1 \cdot 2 \%)$.

\section{Discussion}

In patients with HCM, the development of atrial fibrillation may lead to clinical deterioration involving acute or progressive cardiac failure and systemic thromboembolism, or potentially lethal ventricular arrhythmias. ${ }^{1-9}$ Moreover, in a previous study based on a largely unselected regional population of patients with $\mathrm{HCM}^{8}$ atrial fibrillation proved to be a particularly common and unfavourable clinical feature, associated with death due to disease progression and heart failure. ${ }^{8}$ These observations underline the advantage of defining clinical markers that would non-invasively identify those patients with HCM who are at risk of developing atrial fibrillation.

Signal averaged $\mathrm{P}$ wave duration has been proposed as a variable that identifies the risk for atrial fibrillation in a variety of clinical conditions. ${ }^{11214-17}$ The rationale for using this test is based on the hypothesis that atrial fibrillation is a reentrant rhythm produced by depressed conduction, which may result in prolonged atrial activation. ${ }^{14}{ }^{25}$ It has been suggested that in certain cardiac diseases atrial depolarisation may be fragmented and prolonged, in part because of left atrial enlargement. ${ }^{126}$ Therefore, in the present study, a large unselected population of patients with HCM who were part of a regional cohort followed at our institution for up to 20 years $^{8}$ were studied with high resolution, signal averaged electrocardiography to assess $P$ wave duration. This analysis excluded patients with chronic atrial fibrillation and was limited to those in sinus rhythm, whether or not they had experienced paroxysmal episodes of atrial fibrillation. We found that the overall study group of $110 \mathrm{HCM}$ patients showed significantly greater filtered $P$ wave duration than controls without cardiovascular disease of similar age.

During the period of follow up, about $40 \%$ of the patients with HCM developed clinically overt paroxysmal atrial fibrillation or had evidence of atrial fibrillation on the Holter ECG before or after recording the signal averaged electrocardiogram. Those patients with atrial fibrillation showed substantially longer $P$ wave duration than patients who remained in sinus rhythm without atrial fibrillation. Indeed, among the several clinical and demographic variables, a multivariate analysis showed that $P$ wave duration was the only independent marker of the propensity to develop atrial fibrillation. A cut off value of $\geqslant 140 \mathrm{~ms}$ for $P$ wave duration showed sensitivity of $56 \%$ and specificity of $83 \%$ in detecting atrial fibrillation, with a positive predictive accuracy of $66 \%$. The probability of developing atrial fibrillation in a patient with $\mathrm{P}$ wave duration of $\geqslant 140 \mathrm{~ms}$ was over three times greater than that of a patient with a $\mathrm{P}$ wave duration of $<$
140 ms.

While most of our patients with clinically overt atrial fibrillation had experienced this arrhythmia before their signal averaged electrocardiogram, almost one quarter of them developed atrial fibrillation following this test. In the latter patients, $P$ wave duration was virtually identical to that of the patients with previously documented atrial fibrillation.

$P$ wave duration showed weak correlation with greater left atrial size, supporting the hypothesis that prolongation of the signal averaged $P$ wave and left atrial enlargement may act as relatively independent factors in promoting atrial fibrillation. Indeed, specificity and positive predictive accuracy for atrial fibrillation improved to $93 \%$ and $78 \%$, respectively, when a left atrial dimension of $>40 \mathrm{~mm}$ was combined with $\mathbf{P}$ wave prolongation $(\geqslant 140 \mathrm{~ms})$ in this analysis.

Of note is the subgroup of 23 patients in whom there was no prior history of a clinically evident episode of atrial fibrillation, although a Holter recording did identify prolonged periods of this arrhythmia. With regard to filtered $P$ wave duration, this subgroup with "silent atrial fibrillation" proved to be intermediate between patients with clinical atrial fibrillation and those without atrial fibrillation. These findings support the hypothesis that occult atrial fibrillation, present only on Holter, in patients with HCM may be an antecedent to the clinically overt expression of this arrhythmia and suggest that Holter electrocardiographic recordings in conjunction with the measurement of $\mathrm{P}$ wave duration (as well as assessment of left atrial enlargement by echocardiography) may enhance the identification of those patients at risk for developing atrial fibrillation. Further substantiation of this view is our observation that almost $75 \%$ of our patients with clinical atrial fibrillation had also shown asymptomatic episodes of atrial fibrillation on Holter monitoring before their signal averaged electrocardiographic recording.

We do not think that the drug treatment to which many patients in our study group were exposed influenced our data or the conclusions regarding $\mathbf{P}$ wave duration. Cardioactive drugs - with the exception of amiodaronewere discontinued for a sufficient period of time before the signal averaged electrocardiographic recordings. Although the administration of amiodarone was associated with $P$ wave prolongation, multivariate analysis showed that a $P$ wave of $\geqslant 140 \mathrm{~ms}$ in duration retained a highly significant association with atrial fibrillation, which was independent of the effect of amiodarone treatment. Also, the statistically significant difference in $P$ wave duration between patients with clinical atrial fibrillation and those without atrial fibrillation was not altered by the exclusion of those patients to whom amiodarone was administered.

In the present study, we employed an $R$ wave triggered technique for signal averaging which derives a longer $P$ wave duration and a lower amplitude than the $\mathbf{P}$ wave triggered techniques employed by certain other investi- 
gators. ${ }^{11-132223}$ However, in our experience, ${ }^{17}$ significant differences in $\mathrm{P}$ wave duration are not detectable between the two triggering modes provided patients are at absolute rest just before the recording.

An unavoidable limitation to the present investigation is its largely retrospective design. However, given the dynamic and slowly evolving process of atrial fibrillation in patients with $\mathrm{HCM}^{18}$ a truly prospective study would have required substantial periods of observation, impractical for any clinical investigation. Nevertheless, on the basis of the findings of our study we believe that it is feasible to assess the risk for developing atrial fibrillation in patients with HCM, and that measurement of signal averaged $P$ wave duration may play an important role in the longitudinal assessment of this clinical problem.

1 Maron BJ, Bonow RO, Cannon RO, Leon BM, Epstein SE. Hypertrophic cardiomyopathy: interrelation of clinical manifestations, pathophysiology, and therapy. $N$ Engl f Med 1987;316:780-9,844-52.

2 Robinson KC, Frenneaux MP, Stockins B, Karatasakis G, Poloniecki JD, McKenna WJ. Atrial fibrillation in hypertrophic cardiomyopathy: a longitudinal study. $\mathcal{F} \mathrm{Am}$ Coll trophic cardiomyopathy: a

3 Wigle ED, Sasson Z, Henderson MA, Ruddy TD, Fulop J, Rakowski $\mathrm{H}$, et al. Hypertrophic cardiomyopathy: the importance of the site and extent of hypertrophy-a review. Progr Cardiovasc Dis 1985;28:1-83.

4 Spirito P, Lakatos E, Maron BJ. Degree of left ventricular hypertrophy in chronic atrial fibrillation in hypertrophic cardiomyopathy. Am $\mathcal{F}$ Cardiol 1992;69:121 7-22.

5 Henry WL, Morganroth J, Pearlman AS, Clark CE, Redwood DR, Itscoitz SB, et al. Relation between echocardiographically determined left atrial size and atrial fibrillation. Circulation 1976;53:273-9.

6 Glancy DL, O'Brien KP, Gold HK, Epstein SE. Atrial fibrillation in patients with idiopathic hypertrophic subaortic stenosis. Br Heart $\mathcal{F} 1970 ; 32: 652-9$.

7 Stafford WJ, Trohman RG, Bilsker M, Zaman L, Castellanos A, Myerburg RJ. Cardiac arrest in an adolescent with atrial fibrillation and hypertrophic cardiomyopathy. F Am Coll Cardiol 1986;7:701-4.

8 Cecchi F, Olivotto I, Montereggi A, Santoro G, Dolara A, Maron BJ. Hypertrophic cardiomyopathy in Tuscany: clinical course and outcome in an unselected regional population. F Am Coll Cardiol 1995;26:1529-36.

9 Madariaga I, Carmona JR, Mateas FR, Lezaun R, de los Arcos E. Supraventricular arrhythmia as the cause of sudden death in hypertrophic cardiomyopathy. Eur Heart 7 1994;15:134-7.

10 Maia IG, Filho FESC, Fagundes MLA, Boghossian SH,
Vanheusden L, Sa RM, et al. Signal-averaged $P$ wave in patients with Wolff-Parkinson-White syndrome after successful radiofrequency catheter ablation. $7 \mathrm{Am}$ Coll Cessful radiofrequency cath

11 Fukunami M, Yamada $T$, Ohmori $M$, Kumagai $K$, Umemoto $\mathrm{K}$, Sakai A, et al. Detection of patients at risk for paroxysmal atrial fibrillation during sinus rhythm by $P$ wave-triggered signal-averaged electrocardiogram. Circulation 1991;83:162-9.

12 Guidera SA, Steinberg JS. The signal-averaged $P$ wave duration: a rapid and noninvasive marker of risk of atrial fibrillation. F Am Coll Cardiol 1993;21:1645-51.

13 Stafford PJ, Turner I, Vincent R. Quantitative analysis of signal-averaged $P$ waves in idiopathic paroxysmal atrial fibrillation. Am $\mp$ Cardiol 1991;68:751-5.

14 Steinberg JS, Zelenkofske S, Wong SC, Gelernt M, Sciacca $R$, Menchavez E. Value of signal-averaged ECG for predicting atrial fibrillation after cardiac surgery. Circulation 1993;88:2618-22.

15 Montereggi A, Marconi P, Olivotto I, Castelli G, Dolara A, Luisi ML, et al. Signal-averaged $P$ wave duration and risk of atrial fibrillation in hyperthyroidism. Am $\exists$ Cardiol 1996;77:266-9.

16 Marconi P, Montereggi A, Marioni C, Castelli G. Signalaveraged electrocardiogram in patients with paroxysmal lone atrial fibrillation. New Trends in Arrhythmias 1992;8: 277-81.

17 Marconi P, Montereggi A, Sarro F, Castelli G. "Signal averaging" dell'onda P: la problematica dell'allineamento del segnale. Cardiostimolazione 1993;11:135-8.

18 Maron BJ, Epstein SE. Hypertrophic cardiomyopathy: a discussion

19 Maron BJ, Gottdiener JS, Epstein SE. Patterns and significance of the distribution of left ventricular hypertrophy in hypertrophic cardiomyopathy: a wide-angle, two-dimenhypertrophic cardiomyopathy: a wide-angle, two-dimenSional echocardiographic $1981 ; 48: 418-28$.

20 Sasson Z, Yock PG, Hatle LK, Alderman EL, Popp RL. Doppler echocardiographic determination of the pressure gradient in hypertrophic cardiomyopathy. $\mathcal{F} \mathrm{Am}$ Coll Cardiol 1988:11:752-6.

21 Panza JA, Petrone RK, Fananapazir L, Maron BJ. Utility of continuous wave Doppler in noninvasive assessment of the left ventricular outflow tract pressure gradient in patients with hypertrophic cardiomyopathy. $\mathcal{F} \mathrm{Am}$ Coll Cardiol 1992;19:91-9.

22 Simson MB. Use of signals in the terminal QRS complex to identify patients with ventricular tachycardia after myocardial infarction. Circulation 1981;64:235-42.

23 Scott WA, Donnerstein RL. Alignment of $P$ waves for signal averaging. PACE 1990;13:1559-62.

24 Hosmer DW, Lemeshow S. Applied logistic regression. New York: John Wiley, 1989.

25 Janse MJ, Allessie MA. Experimental observations in atrial fibrillation. In: Falk RH, Podrid PJ, eds. Atrial fibrillation: mechanism and management. New York: Raven Press; 1992:41-58

26 Ohe T, Matsuhisa M, Kamakura S, Yamada J, Sato I, Nakajima $K$, et al. Relation between the widening of the fragmented atrial activity zone and atrial fibrillation. $A m \mathcal{F}$ Cardiol 1983;53:1219-22.

27 Maron BJ, Roberts WC. Hypertrophic cardiomyopathy. In: Schlant RC, Alexander RW, eds. Hurst's The heart, 8th ed, chapter 90. Baltimore: McGraw-Hill, 1994:1621-35. 